\title{
A STUDY OF MAXIMUM OXYGEN UPTAKE AND HEART RATE DURING WORK AND RECOVERY AS MEASURED ON CYCLE ERGOMETER ON NATIONAL INDIAN SPORTSMEN
}

\author{
S. K. VERMA, ${ }^{1}$ MSc, L. S. SIDHU, ${ }^{2}$ MSc, PhD, and D. K. KANSAL, ${ }^{3}$ MSc \\ Research Centre in Physical Education and Sports and Department of \\ Human Biology, Punjabi University, Patiala, India
}

\begin{abstract}
We have studied 73, top level Indian sportsmen for $\mathrm{VO}_{2} \max$ and heart rates during work and recovery. High negative values of ' $r$ ' between $\mathrm{VO}_{2} \max$ and heart rate during work and recovery have been observed. Absolute $\mathrm{VO}_{2} \max _{1} \mathrm{VO}_{2}$ $\mathrm{max} / \mathrm{kg}$ body $\mathrm{wt} / \mathrm{min}$ and $\mathrm{VO}_{2} \mathrm{max} / \mathrm{kg}$ lean body mass $/ \mathrm{min}$ are found to play an important role in influencing recovery of heart rate, more so in the initial phases. A similar trend has been observed while studying the influence of work heart rate on the recovery of heart rate after a standard exercise. Regression equations for the prediction of $\mathrm{VO}_{2}$ max from recovery pulse scores, have been worked out for Indian sportsmen.
\end{abstract}

\section{INTRODUCTION}

It is an established fact that maximum oxygen uptake $\left(\mathrm{VO}_{2}\right.$ max) plays an important role in the determination of physical work capacity under aerobic conditions (Åstrand 1956, Newton 1963, Ribisl and Kachadorian 1969) and it is superior to any other single test for evaluating physical work capacity (Åstrand and Rodahl 1970 and de Vries 1975). Various other investigators (Åstrand and Saltin 1961, Batke 1963, Cooper 1968, Taylor et al 1955, Doolittle and Bigbee 1968) have supported the idea of utilising maximum oxygen uptake as a measurement of cardiorespiratory fitness.

The direct determination of aerobic power i.e. the maximum oxygen uptake is time consuming and requires both expensive equipment and highly trained technicians. Certain difficulties may also be encountered while carrying out this test on older people and it is impracticable for use with large groups (Jokl 1958, Shephard 1969). Because of these difficulties there is a need to link $\mathrm{VO}_{2}$ max with some simple physiological parameter which might indirectly allow the measurement of $\mathrm{VO}_{2}$ max. Most of the tests for the determination of physical work capacity are based on a linear relationship of work heart rate and oxygen uptake or work intensity (Kamon and Kent 1972, Magel 1971, Maritz 1961). If the position and slope of this line is determined from measurements made during submaximal exercise then it is possible to predict probable values of physical work capacity. Shapiro et al, 1976, achieved further simplification of these tests in which $\mathrm{VO}_{2} \max$ was predicted from the

\footnotetext{
S. K. Verma: Senior Research Associate

L. S. Sidhu: Reader \& Head of Human Biology Department

D. K. Kansal: Research Associate
}

recovery heart rates after submaximal exercise. In these tests heart rate was measured at the beginning of recovery in the period $5.15 \mathrm{~s}$ after cessation of work. According to Shapiro et al heart rate during first 5-15 s of the recovery is influenced by work heart rate and $\mathrm{VO}_{2}$ max. However, he has not studied what happens in the subsequent part of recovery. In the present study we have to be concerned with the relationship of $\mathrm{VO}_{2} \max$ and work heart rate with recovery pulse during different phases of recovery after cessation of standard work at $150 \mathrm{~W}$ for $3 \mathrm{~min}$ on a cycle ergometer. Equations for the prediction of $\mathrm{VO}_{2}$ max from the heart rate during work and recovery for Indian sportsmen have also been worked out. Perhaps this is the first such study on Indian athletes and sportsmen.

\section{MATERIALS AND METHODS}

The study was conducted on 73 Indian national sportsmen belonging to 3 different sports disciplines viz. basketball, hockey and athletics, during their training camps at the Netaji Subhash National Institute of Sports. They were from different parts of India and included Pathans, Tamils and Punjabis.

$\mathrm{VO}_{2}$ max of all the sportsmen was determined by a progressive step-increment test using an electronically controlled cycle ergometer. Each subject was required to pedal at a constant rate of 45 r.p.m. with the help of a tachometer.

The selection of the pedalling speed for the aerobic power test was left to the subjects so as to suit them. Majority of the subjects of this study chose 45 r.p.m. as the pedalling speed. So to keep uniformity, the above said speed was selected for all the subjects. In choosing this speed, there was no limitation of the cycle ergo- 
meter. The speed of our cycle ergometer can go up to 90 r.p.m.

The exercise test was started at a relatively light work rate of $150 \mathrm{~W}$. Every 3 min thereafter the work load was increased by $20 \mathrm{~W}$ until the subject stopped pedalling. During the test each subject was verbally encouraged to pedal for as long as possible. The test was terminated when the subject could no longer maintain the pedalling rate. Subjects breathed through a dry gas meter during exercise and expired air gas samples were collected at the end of each work load. The gas samples were analysed for $\mathrm{CO}_{2}$ and $\mathrm{O}_{2}$ using Haldane's technique. $\mathrm{VO}_{2}$ max was chosen as the highest observed oxygen uptake value in the series of consecutive $\mathrm{O}_{2}$ measurements.

Each subject was asked to report again for a submaximal exercise test which was conducted within 3-4 days after the determination of $\mathrm{VO}_{2} \max$. For this test the subject was asked to pedal the cycle ergometer at a constant rate of 45 r.p.m. for $3 \mathrm{~min}$ at $150 \mathrm{~W}$. The heart rate was measured after every minute during exercise and recovery. However, first recovery pulse was recorded from 15-30 s after cessation of exercise. Lean body mass (LBM) was calculated by using the formula given by Durnin and Rahman (1967).

\section{RESULTS AND DISCUSSION}

Table I gives the mean, standard deviation and coefficient of variation of various physiological and morphological parameters studied on 73 Indian national sportsmen. Most of the parameters have shown a high degree of variation, one reason for this variability may be that the sportsmen in this study belong to different physical activities. The absolute $\mathrm{VO}_{2} \max$ shows the maximum value of coefficient of variation, however, when $\mathrm{VO}_{2}$ max is expressed in terms of body weight or LBM, the value decreased considerably.

\section{TABLE I:}

Means and Standard Deviations of various Physiological and Morphological Parameters studied in Indian national sportsmen.

Parameter

1. $\mathrm{VO}_{2} \max (1 / \mathrm{min})$

2. $\mathrm{VO}_{2} \max (\mathrm{ml} / \mathrm{kg} / \mathrm{min})$

3. $\mathrm{VO}_{2} \max (\mathrm{ml} / \mathrm{kg} \mathrm{LBM} / \mathrm{min})$

4. Absolute lean body mass (LBM) in $\mathbf{~ k g}$

5. Body Weight in $\mathrm{kg}$

6. Work heart rate at $150 \mathrm{~W}$ of work load (beats/min)

7. Recovery pulse $\mathbf{1 5 - 3 0 ~ s}$ (beats/15 s)

8. Recovery pulse 60-75 s

9. Recovery pulse $120-135 \mathrm{~s}$

Means S.D.

Coefficient of Variance

The correlation coefficient ' $r$ ' computed among various parameters is given in Table II. The high negative values of ' $r$ ' between $\mathrm{VO}_{2}$ max and heart rate during work and recovery suggest that the higher values of $\mathrm{VO}_{2}$ max in sportsmen are responsible for lower heart rates during work and subsequent recovery. We found that absolute $\mathrm{VO}_{2}$ max has a very high relationship with work heart rate and recovery pulse of 15-30 s. However, a significant relationship of $\mathrm{VO}_{2} \max$ also existed with the later phase of recovery but the magnitude of relationship was found to decrease considerably after first minute of recovery. The values of correlation coefficients between $\mathrm{VO}_{2}$ max and the various recovery pulse scores, especially with the later phase of recovery, improved considerably when the former was expressed in terms of body weight or LBM. Further it is interesting to note that the recovery pulse score of a particular period has a lesser value of ' $r$ ' with $\mathrm{VO}_{2}$ max (expressed

TABLE II:

Correlation Table of Parameters in Table I

\begin{tabular}{|c|c|c|c|c|c|c|c|}
\hline Parameter & 2 & 3 & 4 & 5 & 6 & 7 & 8 \\
\hline 1. $\operatorname{Max} \mathrm{VO}_{2}$ & 0.563 & 0.660 & 0.850 & -0.765 & -0.632 & -0.343 & -0.379 \\
\hline 2. $\mathrm{VO}_{2} \mathrm{max} / \mathrm{kg} / \mathrm{min}$ & & 0.910 & $0.106^{*}$ & -0.700 & -0.720 & -0.670 & -0.570 \\
\hline 3. $\mathrm{VO}_{2} \max / \mathrm{kg} \mathrm{LBM} / \mathrm{min}$ & & & $0.184^{*}$ & -0.670 & -0.697 & -0.518 & -0.505 \\
\hline 4. Absolute lean body mass & & & & -0.514 & -0.330 & $-0.086^{*}$ & $-0.120^{*}$ \\
\hline 5. Work heart rate & & & & & 0.860 & 0.696 & 0.556 \\
\hline 6. $15-30$ s Recovery pulse & & & & & & 0.800 & 0.737 \\
\hline 7. 60-75 s Recovery pulse & & & & & & & 0.872 \\
\hline
\end{tabular}

8. 120-135 s Recovery pulse

*Values non-significant at $5 \%$ level 
in terms of body weight or LBM) as compared to that of its preceding recovery pulse score indicating thereby a clear deteriorating effect of recovery time on the relationship between $\mathrm{VO}_{2} \max$, and recovery pulse scores. This indicates that $\mathrm{VO}_{2} \max , \mathrm{VO}_{2} \mathrm{max} / \mathrm{kg}$ body $\mathrm{wt} / \mathrm{min}$ and $\mathrm{VO}_{2} \mathrm{max} / \mathrm{kg} \mathrm{LBM} / \mathrm{min}$ play an important role in influencing the recovery. In the initial part of recovery the role of these parameters is well marked, but it decreases with the progress of recovery.

The high relationship of $\mathrm{VO}_{2} \mathrm{max} / \mathrm{kg}$ body wt/min with the 15-30 s and 60-75 $\mathrm{s}$ recovery pulse observed in our study support the earlier findings of McArdle et al (1972). However, the absolute $\mathrm{VO}_{2}$ max in this study correlated moderately well with the recovery pulse scores which differs from the observations of McArdle et al. This may be due to the sex differences involved between the choice of subjects and different exercises chosen in the two studies. We used a cycle ergometer to deliver standard exercise while McArdle et al used the step test.

The high values of correlation coefficients between $\mathrm{VO}_{2} \max$ and different recovery pulse scores also suggests that recovery pulse scores of different intervals after cessation of a standard exercise can give a good measure of $\mathrm{VO}_{2}$ max. The regression lines for the prediction of $\mathrm{VO}_{2} \max , \mathrm{VO}_{2} \max / \mathrm{kg}$ body $\mathrm{wt} / \mathrm{min}$ and $\mathrm{VO}_{2}$ $\mathrm{max} / \mathrm{kg} \mathrm{LBM} / \mathrm{min}$ from the heart rate during work and recovery after a standard submaximal exercise at $150 \mathrm{~W}$ for $3 \mathrm{~min}$ on the ergometer are illustrated in Figs 1,2 and 3 respectively.

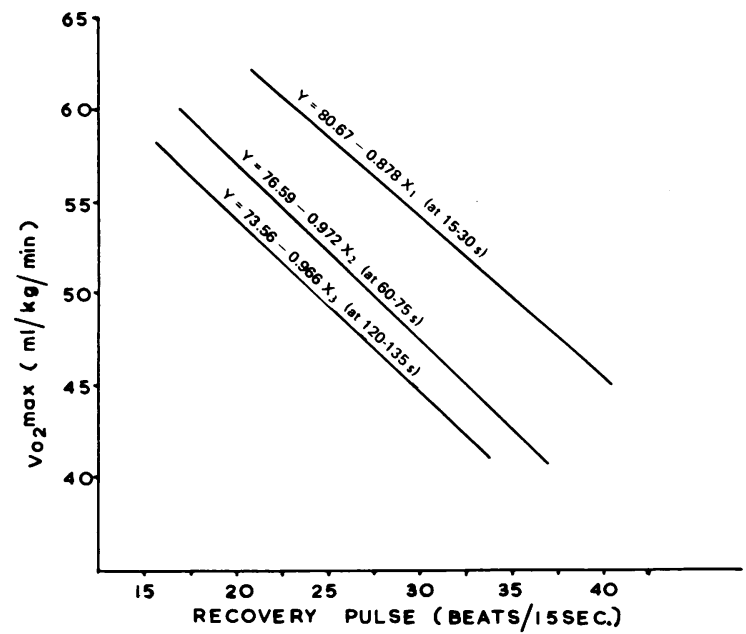

Fig 1: Regression lines for predicting maximum $\mathrm{VO}_{2}$ $(\mathrm{ml} / \mathrm{kg} / \mathrm{min})$ from the recovery heart rate scores.

The correlation coefficient of work heart rate with all the three phases of recovery viz. $15-30 \mathrm{~s}, 60-75 \mathrm{~s}$, and $120-135$ s recovery pulse scores is found to be $.860, .696$

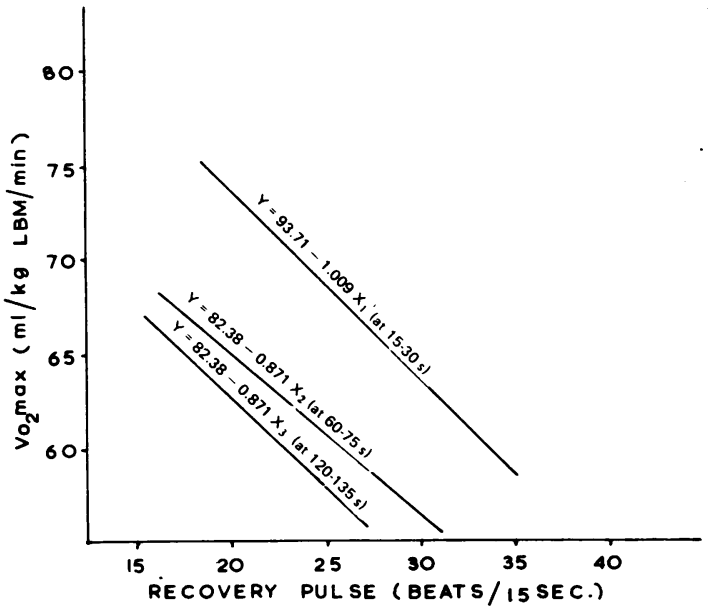

Fig 2: Regression lines for predicting maximum $\mathrm{VO}_{2}$ $(\mathrm{ml} / \mathrm{kg} L B M / \mathrm{min})$ from the recovery heart rate scores.

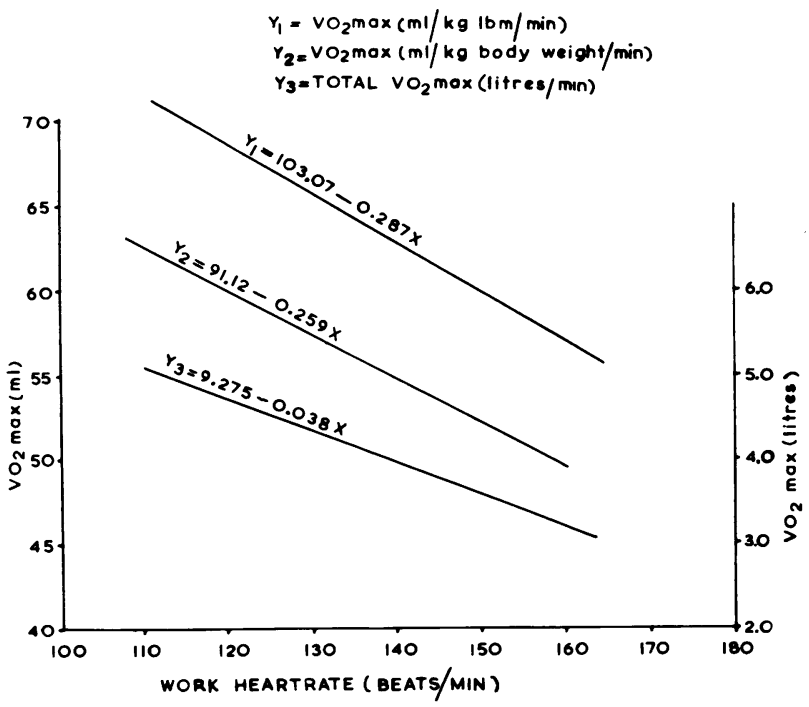

Fig 3: Regression lines for prediction of $\mathrm{VO}_{2}$ max from work heart rate

and .556 respectively (Table II). It is observed that all the values of ' $r$ ' are highly significant. It is evident from these values that the magnitude of relationship between work heart rate and recovery pulse scores decreases as the recovery advances. The high correlation between work heart rate and $15-30$ s recovery pulse agrees with the earler reported observations of Shapiro et al (1976), but in our study the correlation obtained is 0.86 as compared to 0.98 reported by Shapiro et al (1976). This may be be due to the different timings of recovery pulse chosen in the two studies. We have used $15-30$ s for our 


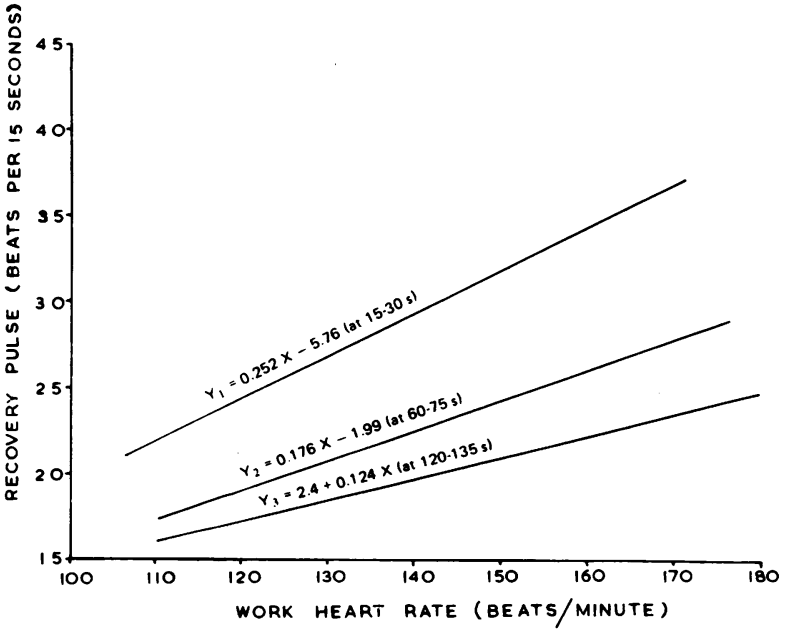

Fig 4: Regression line of recovery pulse upon work heart rate first $15 \mathrm{~s}$ recovery period, whereas Shapiro et al used 5-15 $\mathrm{s}$ which is an earlier counting period than we could use. This also shows that the influence of work heart rate on recovery decreases as the recovery advances.

It is well established that a linear relationship exists between work heart rate and oxygen intake at submaximal work loads, but the same relationship does not exist during recovery. The factors which govern the rate of decrease of heart rate during recovery are not well investigated. Further it is reported by many investigators that the magnitude of work done determines the rate of decrease of heart rate during recovery (Royce 1969, Cotten 1971, McArdle et al 1969, Ryhming 1953 and Shephard 1966). In our study it is shown that the recovery heart at the beginning of recovery is strongly influenced by the heart rate during work and $\mathrm{VO}_{2}$ max. The subsequent part of recovery however, is also influenced by the $\mathrm{VO}_{2} \max$ and work heart but the influence of these parameters on recovery heart rate decreases as the recovery progresses.

\section{REFERENCES}

Åstrand P. O., 1956. "Human physical fitness with special reference to sex and age." Physiol.Rev. 36: 308.

Åstrand P. O. and Rodahl K., 1970. "Text book of work Physiology." McGraw-Hill, New York. 314.

Åstrand P. O. and Saltin B. S., 1961. "Maximum oxygen uptake and heart rate in various types of muscular activity." J.Appl.Physiol. 16: 977-981.

Balke B., 1963. "A simple field test for the assessment of physical fitness." Rpt. 63-6, Oklahoma City, EARI, FAA, April.

Cooper K. H., 1968. "A means of assessing maximum oxygen uptake: correlation between field and treadmill testing." J.Am.Med.Assn. 203: 201-204

Cotten D. T., 1971. "A modified step test for grouped cardiovascular testing." Res. Quart. 42: 91.

de Vries H. A., 1975. "Physiology of exercise for physical education and athletes." Dubuque, Wm. C. Brown Co. IOUW, 229.

Doolittle T. L. and Bigbee R., 1968. "The twelve minute run walk: a test of cardiorespiratory fitness of adolescent boys." Res.Quart. 39: 491-495.

Durnin J. V. G. A. and Rahman M. M., 1967. "The assessment of the amount of fat in the human body from measurements of skinfold thickness." Brit.J.Nutr. 21: 681-689.

Jokl E., 1958. "The clinical physiology of physical fitness and rehabilitations." C. C. Thomas, Springfield, Illinois.

Kamon E. and Kent B. P., 1972. "Maximal aerobic power during treadmill running, uphill climbing and cycling." J.Appl.Physiol. 32: 467.

Magel J. R., 1971. "Comparison of physiological response to a varying of submaximal work in swimming and treadmill running." J.Sports Med.and Physical Fitness. 11: 203. 
Maritz J. S., Morrison J. F., Peter J., Strydom N. B. and Wyndham C. H., 1961. “A practical method of estimating an individuals maximum oxygen uptake." Ergonomics 4: 97.

McArdle D. W., Katch F. I., Pechar G. S., Jacobson L. and Ruch S., 1972. "Reliability and interrelationships between maximum oxygen intake, physical work capacity and step test scores in college women." Med.\& Sci.in Sports. 4: $182-186$.

McArdle D. W., Zwiren L., Magel J. R., 1969. "Validity of post exercise heart rate as a means of estimating heart rate during work in various intensities." Res.Quart. 42: 91.

Newton J., 1963. “The assessment of maximum oxygen uptake." J.Sports Med.and Physical Fitness. 3: 164.

Ryhming I., 1953. "A modified Harvard step test for the evaluation of physical fitness." Arbeitsphysiol. $15: 235$.

Ribisl P. H. and Kachadorian W. A., 1969. "Maximal oxygen intake prediction in young men and middle aged males." J.Sports Med.\& Physical Fitness. 9: 17.

Royce J., 1969. "Active and passive recovery from maximal aerobic capacity work." Int.Z.angew.Physiol. $28: 1$.

Shapiro A., Shapiro Y., and Magazanik A., 1976. "A simple test to predict aerobic capacity." J.Sports Med.\& Physical Fitness. 16: 3, 209-214.

Shapiro A., Shoenfeld and Shapiro Y., 1976. "Recovery heart rate after submaximal work." J.Sports Med.and Physical Fitness. 16: 1, 57-59.

Shephard R. J., 1969. Endurance fitness. c.f. Encyclopaedia of Sports Medicine New York, MackMillan.

Shephard R. J., 1966. "On the timing of post exercise pulse readings." J.Sports Med.\& Physical Fitness. 6: 23.

Taylor H. L., Buskirk E. and Henschel A., 1955. "Maximum oxygen intake as an objective measure of cardiorespiratory performance." J.Appl.Physiol. 8: 73-80. 